\title{
A CASE OF CHANCE FINDING OF DISTAL PANCREATIC TUMOUR DURING THE PROCEDURE FOR CHRONIC PANCREATITIS
}

\author{
Probhas Kumar Sarkar1, Saurabh Das², Partha Sarathi Mandal3, Kumar Dheeraj4 \\ 1 Professor, Department of General Surgery, IPGME\&R, SSKM Hospital, Kolkata. \\ ${ }^{2}$ Assistant Professor, Department of General Surgery, IPGME\&R, SSKM Hospital, Kolkata. \\ ${ }^{3}$ Postgraduate Trainee, Department of General Surgery, IPGME\&R, SSKM Hospital, Kolkata. \\ 4Postgraduate Trainee, Department of General Surgery, IPGME\&R, SSKM Hospital, Kolkata.
}

\begin{abstract}
BACKGROUND

Chronic pancreatitis is not a rare surgical entity. Again isolated malignant pancreatic neoplasm is also not a rare entity. But occurrence of malignant pancreatic neoplasm in existing chronic pancreatitis is a rare incidence. Above all making a diagnosis and satisfactory successful treatment in such dual contrasting conditions is difficult and challenging. Preoperative diagnosis, excision of tumour with oncological clearance, simultaneous pancreaticodocholithotomy with successful drainage procedure are complex. Decision making is difficult if the tumour is detected peroperatively on table without preoperative diagnosis or even hints and suspicion. We are going to present such a case of chronic pancreatitis with preoperative diagnosis of dilated main pancreatic duct (MPD) with multiple stones in MPD. There was no hint of mass lesion in pancreas on imaging (USG whole abdomen and CECT whole abdomen).
\end{abstract}

\section{MATERIALS AND METHODS}

A 40-year-old gentleman, known smoker for over 20 years, was admitted with chief complaint of frequent attacks of epigastric pain for 7 months with imaging findings suggestive of chronic pancreatitis (USG and CECT whole abdomen- dilated main pancreatic duct with multiple macrocalculi). Our preoperative diagnosis was chronic pancreatitis for which we planned for Frey procedure. Peroperatively, an exophytic mass of about $5 \mathrm{~cm}$ in diameter was seen in the body of pancreas encroaching to the tail along with calculi in pancreatic duct in head region. We performed distal pancreatectomy with splenectomy along with the drainage procedure for chronic pancreatitis.

\section{RESULTS}

Postoperative recovery was uneventful. Histopathological report revealed moderately differentiated adenocarcinoma of pancreas (pT2N0Mx).

\section{CONCLUSION}

Pancreatic body neoplasm with chronic pancreatitis is seen rarely and if it is detected peroperatively, the plan for modality of treatment is challenging. This type of dual contrasting condition can best be dealt with this logical and aggressive approach like in our patient.

\section{KEYWORDS}

Pancreatic Neoplasm, Chronic Pancreatitis, Frey Procedure, Distal Pancreatectomy with Splenectomy.

HOW TO CITE THIS ARTICLE: Sarkar PK, Das S, Mandal PS, et al. A case of chance finding of distal pancreatic tumour during the procedure for chronic pancreatitis. J. Evolution Med. Dent. Sci. 2017;6(20):1652-1654, DOI: 10.14260/Jemds/2017/363

\section{BACKGROUND}

Case Report

\section{History of Present Illness}

A 40-year-old gentleman, known smoker for over 20 years, was admitted in surgical ward on 30/07/2016 with a chief complaint of frequent attacks of epigastric pain for 7 months with imaging findings suggestive of chronic pancreatitis (USG and CECT whole abdomen- dilated main pancreatic duct with multiple macrocalculi). There was no history suggestive of exocrine insufficiency and the patient was nondiabetic.

Financial or Other, Competing Interest: None.

Submission 30-01-2017, Peer Review 24-02-2017,

Acceptance 01-03-2017, Published 09-03-2017.

Corresponding Author:

Dr. Probhas Kumar Sarkar,

\#70/12,

Bamacharan Roy Road

Kolkata-700034.

E-mail: sarkarprobhas@gmail.com

DOI: $10.14260 /$ jemds $/ 2017 / 363$

\section{(c) (i)}

There was no history of weight loss and anorexia.

\section{Past History}

No history of hospital admission for any ailment previously.

\section{Examination}

General Survey- Mild pallor was present, no enlarged neck glands, no dependent oedema. Local Examination- Abdomensoft, flat, no organomegaly.

\section{Investigations}

Haemoglobin- 10.3 g\%, TLC- 6200 (P71, L27, M1, E1), FBS 95 mg\%, PPBS - 135 mg\%, Urea - 27 mg\%, Creatinine - 0.98 mg\%, Total Bilirubin - 0.4 mg\%, SGPT - 19 U/L, SGOT - 23 $\mathrm{U} / \mathrm{L}$, Alkaline phosphatase - $36 \mathrm{IU} / \mathrm{L}$, Total protein - $8 \mathrm{~g} \%$, Albumin - $4.4 \mathrm{~g} \%$. USG whole abdomen (on 12-07-16) Pancreas is normal in size and shape, heterogeneous in echotexture, 2-3 calculi seen within the pancreatic duct and the pancreatic duct measures $8 \mathrm{~mm}$ (dilated) - suggestive of chronic pancreatitis. 


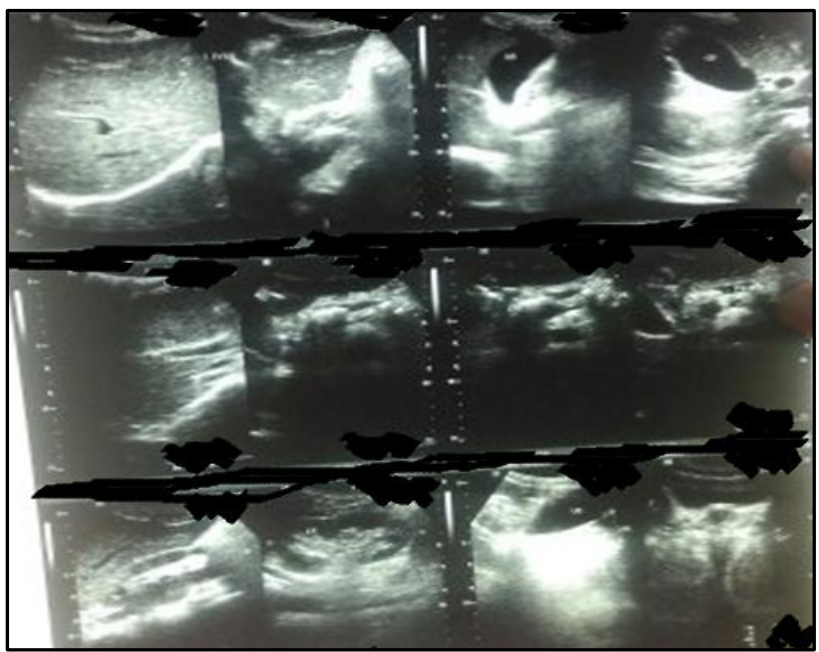

USG Plate of the Patient

CECT whole abdomen (on 20-07-16) - Pancreas is normal in size and shape, no focal area of altered density or enhancement is noted, pancreatic duct is dilated and shows multiple large irregular calculi within.

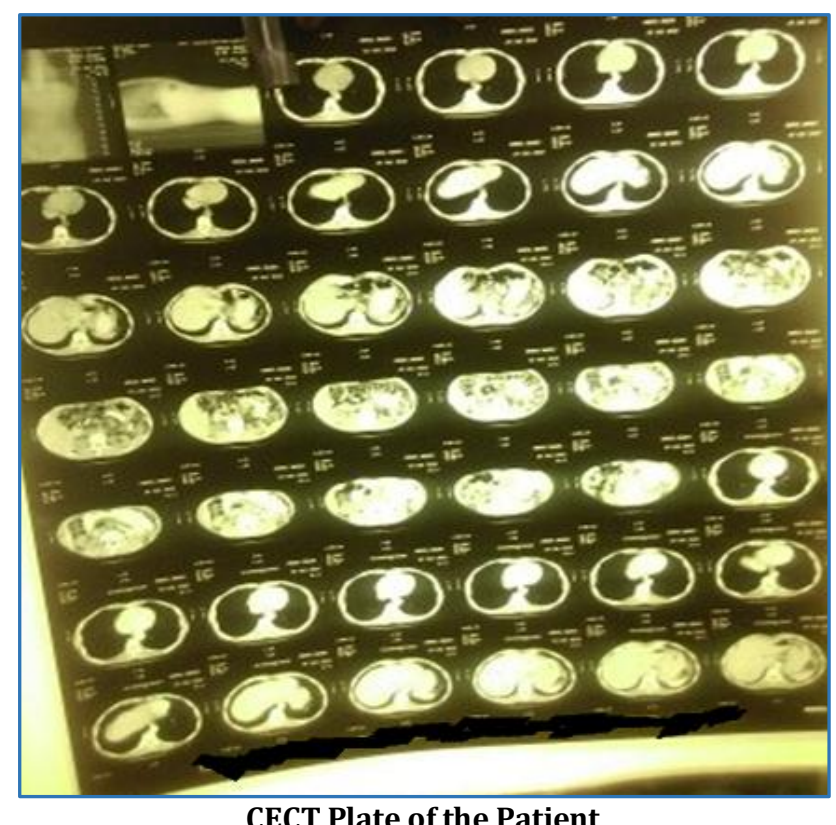

Our preoperative diagnosis was chronic pancreatitis for which Frey procedure was planned.

\section{Peroperative Findings were-}

a) Multiple calculi felt in the pancreatic head.

b) An exophytic mass of about $5 \mathrm{~cm}$ in diameter was seen in the body of pancreas encroaching to the tail.

c) No ascites.

d) No liver metastases.

\section{Procedure}

We planned and performed distal pancreatectomy with splenectomy, segmental omentectomy, pancreaticodocholithotomy, head coring, closure of distal cut end of residual pancreas and lateral pancreaticojejunostomy with cholecystectomy.

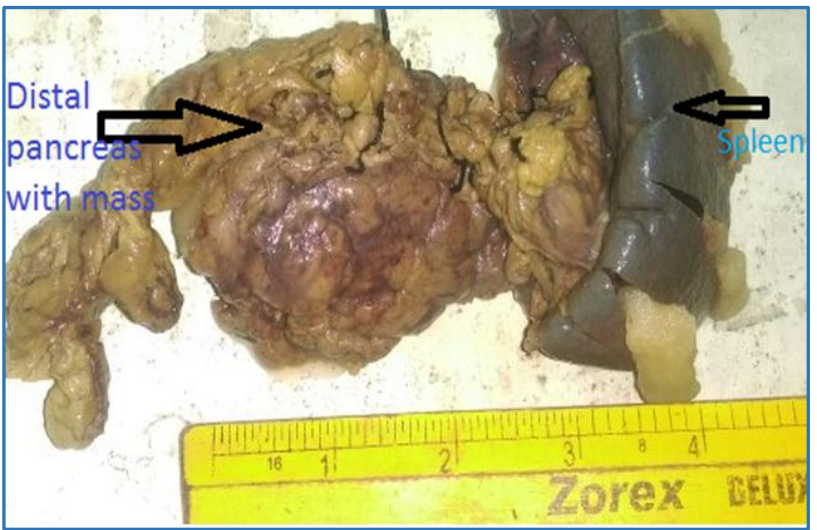

Mounted Specimen of Distal Pancreatectomy with Splenectomy

\section{Post-Operative Period}

Postoperative recovery was uneventful. There was minimum serosanguineous fluid in drainage bag. On $4^{\text {th }}$ postoperative day, drain fluid sent for amylase which showed $28 \mathrm{U} / \mathrm{L}$ (normal). Patient was discharged on $14^{\text {th }}$ postoperative day in stable condition.

\section{Histopathological Report}

1. Sections from the growth of pancreatic body and tail shows moderately differentiated adenocarcinoma of pancreas (pT2N0MX).

2. Sections from pancreatic head shows-normal parenchyma.

\section{DISCUSSION}

The annual incidence of chronic pancreatitis ranges from 5 to 12 per 1 lakh $^{1,2}$ and the prevalence is about 50 per 1 lakh population. ${ }^{2,3}$ The global annual incidence rate for pancreatic cancer is about 8 per 1 lakh population. ${ }^{4}$ Adenocarcinoma is the most frequent type of pancreatic cancer.

In a large multicentre historical cohort study conducted by the International Pancreatitis Study Group, the cumulative risk of pancreatic cancer in patients with chronic pancreatitis was reported as $1.8 \%$ and $4 \%$ at 10 and 20 years respectively. ${ }^{5}$ After extensive search we have not found any literature regarding the incidence of chance finding of distal pancreatic neoplasm during the procedure for chronic pancreatitis.

CT scan is the basic workhorse in suggesting and identifying cancer in chronic pancreatitis and is the most commonly used tool in this setting. Even though multidetector contrast enhanced CT has improved pancreatic resolution and diagnosis - most features of contour and vascular or ductal abnormalities occur in advanced disease. Early pancreatic lesions can still be missed by imaging whilst still curable.

In our case, a neoplasm was detected in the body of pancreas peroperatively without any clue from preoperative USG whole abdomen and CECT whole abdomen. On table we planned and performed distal pancreatectomy with splenectomy, segmental omentectomy, pancreaticodocholithotomy, head coring, closure of distal cut end of residual pancreas and lateral pancreaticojejunostomy with cholecystectomy. Histopathological report confirmed our diagnosis that is the neoplasm was malignant and our approach was logical. 


\section{CONCLUSION}

Pancreatic body neoplasm with chronic pancreatitis is seen rarely and if it is detected peroperatively, the plan for modality of treatment is challenging. This type of dual contrasting condition can best be dealt with this logical and aggressive approach like in our patient.

\section{REFERENCES}

[1] Yadav D, Whitcomb DC. The role of alcohol and smoking in pancreatitis. Nat Rev Gastroenterol Hepatol 2010;7(3):131-45.

[2] Hirota M, Shimosegawa T, Masamune A, et al. The sixth nationwide epidemiological survey of chronic pancreatitis in Japan. Pancreatology 2012;12(2):7984.

[3] Yadav D, Timmons L, Benson JT, et al. Incidence, prevalence, and survival of chronic pancreatitis: a population-based study. Am J Gastroenterol 2011;106(12):2192-9.

[4] Raimondi S, Maisonneuve P, Lowenfels AB. Epidemiology of pancreatic cancer: an overview. Nat Rev Gastroenterol Hepatol 2009;6(12):699-708.

[5] Lowenfels AB, Maisonneuve P, Cavallini G, et al. Pancreatitis and the risk of pancreatic cancer. International pancreatitis study group. $\mathrm{N}$ Engl J Med 1993;328(20):1433-7. 